\title{
Use of anticoagulants increases risk of bleeding after colorectal endoscopic submucosal dissection
}

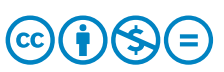

\begin{abstract}
Authors
Institutions

1 Department of Gastroenterology and Metabolism, Hiroshima University Hospital, Hiroshima, Japan

2 Department of Endoscopy, Hiroshima University Hospital, Hiroshima, Japan
\end{abstract}

Ken Yamashita ${ }^{1}$, Shiro Oka ${ }^{1}$, Shinji Tanaka², Kazuki Boda ${ }^{1}$, Daiki Hirano ${ }^{1}$, Kyoku Sumimoto ${ }^{1}$, Takeshi Mizumoto $^{1}$, Yuki Ninomiya', Yuzuru Tamaru', Kenjiro Shigita', Nana Hayashi², Yoji Sanomura², Kazuaki Chayama'

submitted 8.8.2017

accepted after revision 20.2 .2018

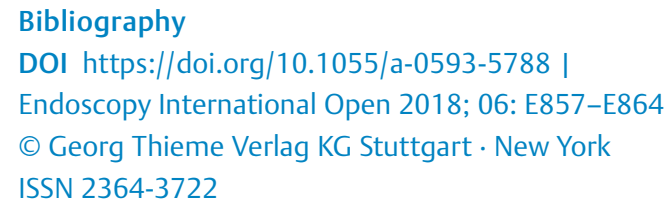

Corresponding author

Shiro Oka, 1-2-3, Kasumi, Minami-ku, Hiroshima 734-8551, Japan

Fax: +81-82-257-5939

oka4683@hiroshima-u.ac.jp

\section{ABSTRACT}

Background and study aims Japanese guidelines for gastroenterological endoscopy have recommended temporary withdrawal of anticoagulants (warfarin, direct oral anticoagulants [DOAC], or heparin) to prevent hemorrhagic complications during endoscopic submucosal dissection (ESD) for colorectal neoplasias (CRNs). However, serious throm- bosis might occur during temporary withdrawal of anticoagulants. The current study aimed to evaluate outcomes with anticoagulants in patients undergoing ESD for CRNs.

Patients and methods This study was a single-institution retrospective cohort study based on clinical records. We assessed 650 consecutive patients with 698 CRNs who underwent ESD at Hiroshima University Hospital between December 2010 and June 2016. The patients were divided into three groups: the warfarin group (19 patients with 19 CRNs), DOAC group (7 patients with 9 CRNs), and no-antithrombotics group (624 patients with 670 CRNs). We replaced warfarin with heparin 3 to 5 days before endoscopy. Although DOAC was suspended on the morning of endoscopy, we did not replace heparin.

Results Bleeding after the procedure occurred in $26.3 \%$ (5/19), $22.0 \%$ (2/9), and $2.7 \%(18 / 670)$ of patients in the warfarin, DOAC, and no-antithrombotics groups, respectively. In the warfarin group, four patients who bled after the procedure took not only warfarin but also other antiplatelets. En bloc resection rates were $94.7 \%$ (18/19), $100 \%$ (9/9), and $96.6 \%(647 / 670)$ in the warfarin, DOAC, and noantithrombotics groups, respectively. No patients experienced ischemic events in the perioperative period.

Conclusions Among patients undergoing ESD for CRNs, risk of bleeding was higher among patients who took anticoagulants than among those who did not. In particular, careful attention to patients who took antiplatelets in addition to warfarin before ESD for CRNs is warranted.

\section{Introduction}

The growth of the elderly population and Westernization of diet in Japan have increased the occurrence of atherosclerotic diseases. Physicians are performing more colonoscopies procedures on patients who receive antithrombotics (antiplatelets and anticoagulants). Risk of thromboembolism may be similar to that of hemorrhage during endoscopic procedures in patients receiving antithrombotics. Thus, management of anticoagulants or antiplatelets has become an important issue. Anticoagulants (warfarin, direct oral anticoagulants [DOACs], and heparin) prevent cerebrovascular disease and deep vein thrombosis. However, brain infarction occurs in approximately $0.6 \%$ to $1 \%$ of patients when anticoagulants are interrupted, which often leads to severely poor outcomes [1,2].

The American Society for Gastrointestinal Endoscopy (ASGE) [3], the European Society of Gastrointestinal Endoscopy (ESGE) [4], and the British Society for Gastroenterology (BSGE) [5] have all published guidelines for management of anticoagulant and antiplatelet therapies in patients undergoing endoscopic procedures. The 2012 Japan Gastroenterological Endoscopy Society (JGES) guidelines [6] recommended that warfarin 
Patients enrollment

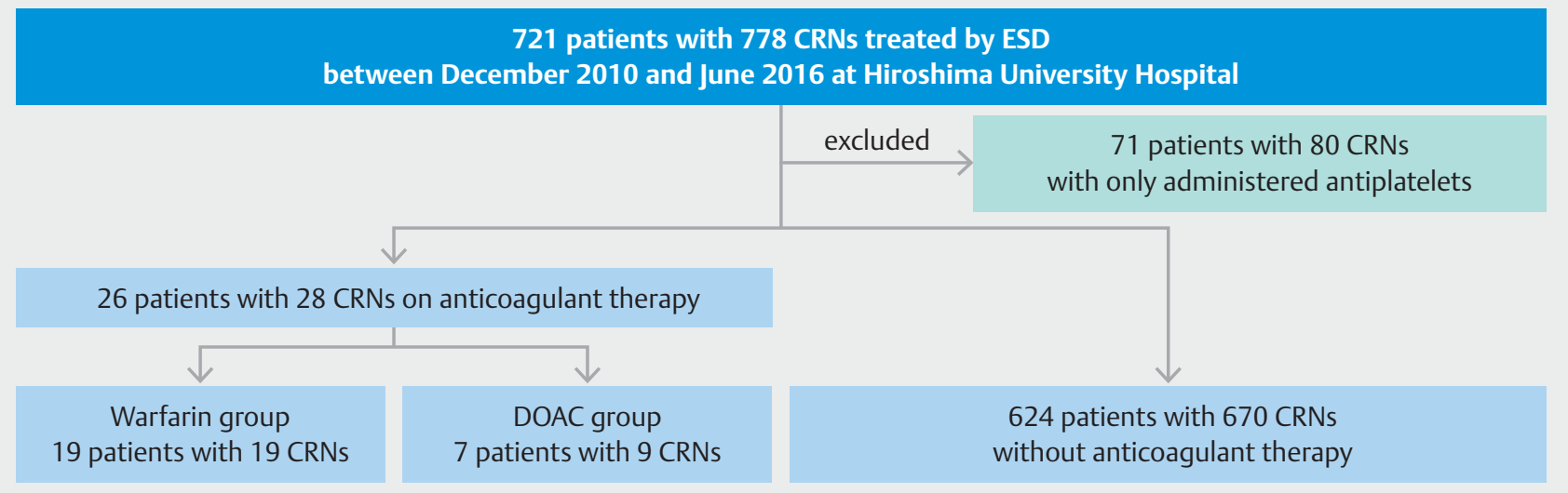

Fig. 1 Patient enrollment in the study. CRN, colorectal neoplasia; ESD, endoscopic submucosal dissection; DOAC, direct oral anticoagulants

should be replaced with heparin prior to endoscopic procedures that carry a high risk of bleeding. The ASGE and BSGE suggested that in low-risk endoscopic procedures, the morning dose of DOAC on the day of the procedure should be omitted. For patients who undergo high-risk endoscopic procedures, the guidelines recommended that the last dose of DOAC should be taken $\geq 48$ hours before the procedure. However, there is little evidence for particular safety zones for treatment or duration of discontinuation when endoscopic treatment is needed during anticoagulant therapy.

Endoscopic submucosal dissection (ESD) has allowed for performance of en bloc tumor resection, regardless of lesion size. ESD is commonly performed for treatment of carcinoma of the upper gastrointestinal tract in Japan [7]. ESD for colorectal neoplasias (CRNs) has also been recognized as a conventional, safe, and efficient therapeutic procedure for years [8-10]. However, complications such as intestinal perforation and delayed bleeding remain problematic $[11,12]$. Therefore, we performed this study to evaluate outcomes with anticoagulant administration in patients undergoing ESD for CRNs.

\section{Patients and methods}

\section{Patients}

We performed a retrospective analysis of 650 patients with 698 CRNs who were treated with ESD at Hiroshima University Hospital between December 2010 and June 2016. The 26 consecutive patients were on anticoagulant therapy (warfarin or DOAC) and underwent ESD for 28 CRNs ( $4.0 \%$ of all cases). Patients not taking antithrombotics were hospitalized the day before ESD, and patients taking warfarin were hospitalized about 1 week before ESD. We performed heparin replacement according to the Hiroshima University Hospital guidelines from 2010 to 2012 and the JGES guidelines from 2012 to 2016 [6]; the guidelines are the same.

Warfarin was replaced with heparin 3 to 5 days before colorectal ESD. The dose of heparin was adjusted to attain the required activated partial thromboplastin time as quickly as pos- sible. Intravenous infusion of heparin was suspended at least 3 hours before the procedure. Warfarin therapy was reinitiated at the pre-withdrawal dose the next day of ESD once hemostasis had been confirmed. Heparin was discontinued when the prothrombin time-international normalized ratio (PT-INR) returned to the therapeutic range. DOAC was suspended on the morning of ESD, and heparin was not replaced. We examined the first stool after ESD, which was not bloody. If hemostasis was confirmed to be present, DOAC was resumed the day after ESD. However, we performed ESD under continued use of antiplatelets, including low-dose aspirin (LDA) in all cases as previously reported [13-15].

The 26 patients who were administered anticoagulants were divided into warfarin (19 patients with 19 CRNs) and DOAC groups (7 patients with 9 CRNs). We also investigated patients who did not take any antithrombotics (624 patients with 670 CRNs). Patients who were only administered antiplatelets ( $\triangleright$ Fig. 1) were excluded. Reasons for using antithrombotics were determined retrospectively using medical records. Use of patient data for the purpose of this study was approved by the Institutional Review Board of Hiroshima University. This study was performed in accordance with the ethical standards laid down in the 1964 Declaration of Helsinki and its later amendments.

\section{Indications and ESD procedure}

Indications of ESD for CRNs were the same as those used in previous reports. ESD was performed by two expert endoscopists. We performed ESD using a high-resolution video colonoscope (CF-H260AZI, PCF-Q260AZI, CF-260JI, or CF-Y0047 [prototype] [Olympus, Japan]) or a gastroscope (GIF-Q260] [Olympus, Japan]) for rectal lesion. Hyaluronic acid-indigo carmine mixed with glycerol was injected to the SM layer using a 21-gauge injection needle. We mixed an equal amount of $0.4 \%$ sodium hyaluronate (MucoUp; Johnson \& Johnson, New Brunswick, New Jersey, United States) and $10 \%$ glycerin solution, and added a small amount of indigo carmine (indigo carmine/MucoUp + glycerin: $0.2 \mathrm{~mL} / 20 \mathrm{~mL}$ ). We mainly used a Dual knife (Olympus, Ja- 
- Table 1 Clinical characteristics of patients with colorectal tumors resected by ESD per group.

\begin{tabular}{|c|c|c|c|c|}
\hline Characteristic of patients & $\begin{array}{l}\text { Total } \\
n=650(\%)\end{array}$ & $\begin{array}{l}\text { Warfarin group } \\
n=19(\%)\end{array}$ & $\begin{array}{l}\text { DOAC group } \\
n=7(\%)\end{array}$ & $\begin{array}{l}\text { No antithrombotics group } \\
n=624(\%)\end{array}$ \\
\hline Age, mean, years old & $66.6 \pm 10.6$ & $74.5 \pm 6.9$ & $75.1 \pm 9.2$ & $66.2 \pm 10.6$ \\
\hline Sex, male & $373(57.4)$ & $12(63.2)$ & $6(85.7)$ & $355(56.9)$ \\
\hline \multicolumn{5}{|c|}{ Reasons for use of anticoagulants } \\
\hline - Arrhythmia & - & $13(68.4)$ & $7(100)$ & - \\
\hline - Ischemic heart disease & - & $4(21.1)$ & $0(0)$ & - \\
\hline - Other & - & $2(10.5)$ & $0(0)$ & - \\
\hline \multicolumn{5}{|l|}{ Use of other antiplatelets } \\
\hline Yes & - & $10(52.6)^{1}$ & $0(0)$ & - \\
\hline - Aspirin & - & $6(31.6)$ & $0(0)$ & - \\
\hline - Clopidogrel & - & $3(15.8)$ & $0(0)$ & - \\
\hline - Dipyridamole & - & $1(5.3)$ & $0(0)$ & - \\
\hline - Ticlopidine & - & $1(5.3)$ & $0(0)$ & - \\
\hline No & - & $9(47.4)$ & $(100)$ & - \\
\hline
\end{tabular}

pan); if possible, we completed ESD with this knife only. Depending on the situation, we also used an IT-knife nano (Olympus, Japan), a Hook knife (Olympus, Japan), and/or an SB knife Jr (Sumitomo Bakelite, Tokyo, Japan). Carbon dioxide insufflation was used instead of room air insufflation. At the end of the procedure, all exposed vessels on the resected ulcer were coagulated with hemostatic forceps (Coagrasper, Olympus, Japan, or HDB2418W-W, Pentax, Japan) in conjunction with a high-frequency generator (ESG-100; Olympus, Japan). Hemostatic forceps rather than endoclips were used when post-ESD hemostasis was necessary. We always performed a blood examination in all patients on the day following ESD. If the blood examination and abdominal findings were not abnormal, the patient was permitted to eat a light meal and leave the hospital within a few days.

\section{Outcomes of ESD}

The following variables were investigated for each group: operation time and rates of en bloc resection, complete en bloc resection, bleeding control during the procedure, bleeding after the procedure, and perforation. We compared these rates among the three groups. Complete en bloc resection was defined as resection of the colorectal tumor with a pathologically negative horizontal margin and a negative vertical margin. Poor control of bleeding during ESD was defined as bleeding that required repeated coagulations by hemostatic forceps $(\geq 10$ times), as previously reported [13-15]. We routinely recorded coagulation times in all cases of ESD. Bleeding after ESD was defined as a decrease in hemoglobin level of $2 \mathrm{~g} / \mathrm{dL}$ or more compared with the last preoperative level, or apparent bleeding or massive melena [16]. These data were collected retrospectively using clinical records.

\section{Statistical analysis}

Quantitative data are shown as mean \pm standard deviation or percentage. Differences in continuous values were analyzed by the chi-square test with the Yates correction, or by the Student's $t$-test. A $P$ value $<0.05$ was considered significant. Propensity score-matching analysis was used to reduce the influence of possible confounding factors (age and sex). JMP statistical software version 12.2.0 (SAS Institute, Cary, NC) was used for all statistical analyses.

\section{Results}

Clinical characteristics of the 26 patients with 28 CRNs treated with warfarin or DOAC (apixaban: 3 patients with 3 CRNs, dabigatran: 2 patients with 2 CRNs, rivaroxaban: 2 patients with 4 CRNs) are shown in $>$ Table 1 . In the warfarin group, warfarin was used for arrhythmia in $68.4 \%$ of patients and for ischemic heart disease in $21.1 \%$. In the DOAC group, DOAC was used for arrhythmia in all patients. Ten patients in the warfarin group used other antiplatelets; however, in the DOAC group, no patients used antiplatelets. The main antiplatelets used in combination with warfarin were aspirin, clopidogrel, and dipyridamole. For patients taking warfarin combined with antiplatelets, we performed ESD under continued use of antiplatelets, and warfarin was replaced with heparin in all cases. There were no significant differences among the warfarin, DOAC, and no-antithrombotics groups in terms of age or sex distribution. Characteristics of the CRNs are shown in $\triangleright$ Table 2 . There were no 
- Table 2 Characteristics of colorectal tumors resected by ESD per group.

\begin{tabular}{|c|c|c|c|c|}
\hline Characteristic of tumors & $\begin{array}{l}\text { Total } \\
n=698(\%)\end{array}$ & $\begin{array}{l}\text { Warfarin group } \\
n=19(\%)\end{array}$ & $\begin{array}{l}\text { DOAC group } \\
n=9(\%)\end{array}$ & $\begin{array}{l}\text { No antithrombotics group } \\
n=670(\%)\end{array}$ \\
\hline \multicolumn{5}{|l|}{ Tumor location } \\
\hline - Right side & $353(50.6)$ & $9(47.4)$ & $3(33.3)$ & 341 (50.9) \\
\hline - Left side & $140(20.1)$ & $1(5.3)$ & $2(22.2)$ & $137(20.4)$ \\
\hline - Rectum & $205(29.4)$ & $9(47.4)$ & $4(44.4)$ & $192(28.7)$ \\
\hline Tumor size (mm) & $33.5 \pm 17.2$ & $41.7 \pm 23.2$ & $39.4 \pm 21.9$ & $32.8 \pm 17.0$ \\
\hline \multicolumn{5}{|l|}{ Macroscopic type } \\
\hline - Protruded & $410(58.7)$ & $12(63.2)$ & $8(88.9)$ & $390(58.9)$ \\
\hline - Superficial & $288(41.3)$ & $7(36.8)$ & $1(11.1)$ & $280(41.1)$ \\
\hline \multicolumn{5}{|l|}{ Pathological diagnosis } \\
\hline - Adenoma & $331(47.4)$ & $6(31.6)$ & $4(44.4)$ & $321(47.9)$ \\
\hline - Tis carcinoma & $234(33.5)$ & $8(42.1)$ & $3(33.3)$ & $223(33.3)$ \\
\hline - T1 carcinoma & $133(19.1)$ & $5(26.3)$ & $2(22.2)$ & $126(18.8)$ \\
\hline
\end{tabular}

differences in tumor size, tumor location, macroscopic type, or pathological diagnosis. Outcomes of patients who underwent ESD for CRNs are shown in $>$ Table 3.

Rates of en bloc resection and complete en bloc resection were $94.7 \%(18 / 19)$ and $89.5 \%(17 / 19)$, respectively, in the warfarin group; $100 \%(9 / 9)$ and $100 \%(9 / 9)$ in the DOAC group, respectively; and $96.6 \%(647 / 670)$ and $95.2 \%(638 / 670)$ in the no-antithrombotics group, respectively. Poor bleeding control during the procedure and bleeding after the procedure occurred in $10.5 \%$ (2/19) and $26.3 \%$ (5/19) of patients, respectively, in the warfarin group; $0 \%(0 / 9)$ and $22.2 \%(2 / 9)$ of patients in the DOAC group, respectively; and 6.6\% (44/670) and $2.7 \%$ $(18 / 670)$ of patients in the no-antithrombotics group, respectively. The perforation rate was $10.5 \%(2 / 19)$ in the warfarin group, $0 \%(0 / 9)$ in the DOAC group, and $5.2 \%(35 / 670)$ in the no-antithrombotics group. The mean operation time was $130.0 \pm 103.2$ minutes in the warfarin group, $95.0 \pm 106.9$ minutes in the DOAC group, and $87.1 \pm 71.0$ minutes in the no-antithrombotics group (there was no statistically significant difference).

The longer mean time of operation in the warfarin group resulted from the longer operations necessary for two patients with poor bleeding control during the procedure (one patient took not only warfarin but also clopidogrel; the other had a lesion with numerous large vessels). Perforation occurred in two patients due to poor endoscopic operability. There were no differences in rates of en bloc resection, complete resection, poor bleeding control during the procedure, perforation, and operation time among the warfarin, DOAC, and no-antithrombotics groups. The rate of bleeding after the procedure was $2.7 \%$ in the no-antithrombotics group, which was significantly lower than the rate of $26.3 \%$ in the warfarin group $(P<0.014 .21$ -
39.78: $95 \% \mathrm{Cl})$ and $22.2 \%$ in the DOAC group $(P<0.052 .01-$ 53.34: $95 \% \mathrm{Cl}$ ).

After propensity score-matching, the rate of bleeding after the procedure in each group is shown in $>$ Table 4 . Propensity score-matching was used to adjust age and sex. The rate of bleeding after the procedure in the no-antithrombotics group was significantly lower than that in the warfarin group. However, there was no significant difference in the rate of bleeding after the procedure among the no-antithrombotics group and the DOAC group. The mean PT-INR at the time of hospitalization of all patients taking warfarin was 1.74 ; in patients taking warfarin who experienced delayed bleeding, it was 1.56 . There was no significant difference. Characteristics of patients with bleeding after ESD for CRNs are shown in > Table 5. In the warfarin group, bleeding after the procedure occurred in four patients who took not only warfarin but also other antiplatelets (clopidogrel, ticlopidine, and LDA). One patient experienced repeated bleeding episodes 4, 5, 6, and 9 days after ESD. That patient also took clopidogrel for post-acute myocardial infarction, which continued during the procedure. One patient in the warfarin group who continued ticlopidine bled on postoperative Day 2. The two patients who were under continued use of LDA experienced bleeding on postoperative Day 1 , when heparin was resumed. There was no significant difference in the rate of bleeding after the procedure between the patients who took only warfarin and the patients who took warfarin + other antiplatelets. In the DOAC group, bleeding occurred in two patients after postoperative Day 1 , when DOAC was resumed. We coagulated all exposed bleeding vessels on the artificial ulcer in all cases, and no patients needed blood transfusion. No patients experienced ischemic events perioperatively. 
- Table 3 Outcomes of ESD for colorectal tumors per group.

\begin{tabular}{|c|c|c|c|c|}
\hline Characteristic of tumors & $\begin{array}{l}\text { Total } \\
n=698(\%)\end{array}$ & $\begin{array}{l}\text { Warfarin group } \\
n=19(\%)\end{array}$ & $\begin{array}{l}\text { DOAC group } \\
n=9(\%)\end{array}$ & $\begin{array}{l}\text { No antithrombotics group } \\
n=670(\%)\end{array}$ \\
\hline \multicolumn{5}{|c|}{ Bleeding after the procedure } \\
\hline - Yes & $25(3.6)$ & $5(26.3)^{\mathrm{a}}$ & $2(22.2)^{b}$ & $18(2.7)^{c}$ \\
\hline - No & $673(96.4)$ & $14(73.7)$ & $7(77.8)$ & $652(97.3)$ \\
\hline \multicolumn{5}{|l|}{ Perforation } \\
\hline - Yes & $37(5.3)$ & $2(10.5)$ & $0(0)$ & $35(5.2)$ \\
\hline - No & $661(94.7)$ & $17(89.5)$ & $9(100)$ & $635(94.8)$ \\
\hline \multicolumn{5}{|c|}{ Bleeding control during the procedure } \\
\hline . Good & $652(93.4)$ & $17(89.5)$ & $9(100)$ & $626(93.4)$ \\
\hline - Poor & $46(6.6)$ & $2(10.5)$ & $0(0)$ & $44(6.6)$ \\
\hline Operation time (min) & $88.0 \pm 72.6$ & $130.0 \pm 103.2$ & $95.0 \pm 106.9$ & $87.1 \pm 71.0$ \\
\hline \multicolumn{5}{|l|}{ En bloc resection } \\
\hline - Yes & $674(96.6)$ & $18(94.7)$ & $9(100)$ & $647(96.6)$ \\
\hline - No & $24(3.4)$ & $1(5.3)$ & $0(0)$ & $23(3.4)$ \\
\hline \multicolumn{5}{|l|}{ Complete en bloc resection } \\
\hline - Yes & $664(95.1)$ & $17(89.5)$ & $9(100)$ & $638(95.2)$ \\
\hline - No & $34(4.9)$ & $2(10.5)$ & $0(0)$ & $32(4.8)$ \\
\hline \multicolumn{5}{|c|}{$\begin{array}{l}\text { ESD, endoscopic submucosal dissection; DOAC, direct oral anticoagulants; CI, confidence interval } \\
\text { a, c a vs. c: } P<0.01 ; 4.21-39.78(95 \% \mathrm{Cl}) \text {. } \\
\text { b, c b vs. c: } P<0.05 ; 2.01-53.34(95 \% \mathrm{Cl}) \text {. }\end{array}$} \\
\hline
\end{tabular}

- Table4 Outcomes of ESD for colorectal tumors per group after propensity-score matching.

\begin{tabular}{|c|c|c|c|}
\hline Characteristic of tumors & $\begin{array}{l}\text { Warfarin group } \\
n=19(\%)\end{array}$ & $\begin{array}{l}\text { No antithrombotics group } \\
n=19(\%)\end{array}$ & $P$ value \\
\hline Age, mean, years old & $74.5 \pm 6.8$ & $74.5 \pm 6.8$ & 1.000 \\
\hline Sex, male & $12(63.2)$ & $12(63.2)$ & 1.000 \\
\hline \multicolumn{4}{|l|}{ Bleeding after the procedure } \\
\hline - Yes & $5(26.3)$ & $0(0)$ & \multirow[t]{2}{*}{0.0164} \\
\hline - No & $14(73.7)$ & $19(100)$ & \\
\hline Characteristic of tumors & $\begin{array}{l}\text { DOAC group } \\
n=9\end{array}$ & $\begin{array}{l}\text { No antithrombotics group } \\
\mathbf{n}=9\end{array}$ & $P$ value \\
\hline Age, mean, years old & $73.3 \pm 8.2$ & $73.3 \pm 8.2$ & 1.000 \\
\hline Sex, male & $8(88.9)$ & $8(88.9)$ & 1.000 \\
\hline \multicolumn{4}{|l|}{ Bleeding after the procedure } \\
\hline - Yes & $2(26.3)$ & $0(0)$ & \multirow[t]{2}{*}{0.1336} \\
\hline - No & $7(73.7)$ & $9(100)$ & \\
\hline
\end{tabular}


- Table 5 Characteristics of cases with bleeding after ESD.

\begin{tabular}{|c|c|c|c|c|c|c|c|c|c|c|}
\hline $\begin{array}{l}\text { No. of } \\
\text { cases }\end{array}$ & $\begin{array}{l}\text { Age } \\
\text { (years) }\end{array}$ & Sex & $\begin{array}{l}\text { Tumor } \\
\text { loction }\end{array}$ & $\begin{array}{l}\text { Tumor } \\
\text { size } \\
(\mathrm{mm})\end{array}$ & $\begin{array}{l}\text { Macro- } \\
\text { scopic } \\
\text { type }\end{array}$ & $\begin{array}{l}\text { Bleeding } \\
\text { control } \\
\text { During } \\
\text { ESD }\end{array}$ & $\begin{array}{l}\text { Opera- } \\
\text { tion } \\
\text { Time } \\
\text { (min) }\end{array}$ & $\begin{array}{l}\text { Other } \\
\text { antithrom- } \\
\text { bobics }\end{array}$ & $\begin{array}{l}\text { Bleeding } \\
\text { date } \\
\text { After ESD } \\
\text { (day) }\end{array}$ & $\begin{array}{l}\text { Anticoagu- } \\
\text { lant restart } \\
\text { date after } \\
\text { ESD (day) }\end{array}$ \\
\hline \multicolumn{11}{|c|}{ Warfarin group } \\
\hline - 1 & 64 & Male & $\mathrm{Rb}$ & 30 & Protruded & Poor & 75 & None & 6,8 & 1 \\
\hline .2 & 89 & Male & $\mathrm{Rb}$ & 50 & Protruded & Poor & 210 & LDA & 1 & 1 \\
\hline . 3 & 75 & Male & $\mathrm{Ra}$ & 35 & Superficial & Good & 20 & Clopidogrel & $4,5,6,9$ & 1 \\
\hline . 4 & 73 & Male & $\mathrm{Ra}$ & 100 & Protruded & Good & 370 & LDA & 1 & 1 \\
\hline .5 & 70 & Female & $\mathrm{T}$ & 40 & Superficial & Good & 45 & Ticlopidine & 2 & 1 \\
\hline \multicolumn{11}{|c|}{ DOAC group } \\
\hline - 1 & 68 & Female & C & 45 & Protruded & Good & 90 & None & 1 & 1 \\
\hline .2 & 84 & Male & RS & 55 & Protruded & Good & 110 & None & $1,4,5,6$ & 1 \\
\hline
\end{tabular}

\section{Discussion}

This study is the first to report that use of anticoagulants increased risk of bleeding in patients who underwent ESD for CRNs compared with those who did not. Results of previous studies on risk of bleeding in patients taking anticoagulants who underwent endoscopic treatment are varied. Fujita et al. [17] reported that gastrointestinal endoscopic biopsy did not increase risk of bleeding despite the fact that antithrombotics were not discontinued prior to biopsy, even among patients taking warfarin whose PT-INR was within the therapeutic range. Inoue et al. [18] reported that post-polypectomy associated with heparin bridge therapy was characterized by high incidence, late onset, and recurrent bleeding, resulting in long hospitalization. Matsumoto et al. [19] also reported that heparin bridging therapy significantly increased risk of post-endoscopy (upper gastrointestinal tract and lower gastrointestinal tract) bleeding compared with the control group. Hui et al. [20] reported a significant increase in post-polypectomy bleeding among patients taking warfarin. In contrast, use of antiplatelets during polypectomy was not associated with an increase in post-polypectomy bleeding. Furthermore, Suzuki et al. [21] reported that lesions located in the cecum and presence of significant bleeding during ESD were independent risk factors for delayed post-ESD bleeding but use of antithrombotics (including heparin) did not yield a significant effect.

In the current study, four of five patients in the warfarin group who bled after ESD took not only warfarin but also antiplatelets. Takeuchi et al. [22] also reported that LDA + warfarin combination therapy was a significant risk factor for bleeding after gastric ESD. Therefore, we should also pay attention to patients who takek multiple antithrombotics including anticoagulants before ESD for colorectal CRNs.

DOAC has been at least as safe and effective as warfarin to prevent stroke and systemic embolism in patients with atrial fi- brillation. Ruff et al. [23] reported that DOAC had a favorable risk-benefit profile, with a significant reduction in stroke, intracranial hemorrhage, and mortality, and with similar rates of major bleeding as warfarin, but increased gastrointestinal bleeding.

LDA is a main drug in antiplatelet therapy to prevent occurrence and recurrence of atherothrombosis. The Japanese guidelines state that it is appropriate to perform high-risk (bleeding risk) gastroenterological endoscopy without interrupting LDA in patients taking LDA as a single agent because of a high risk of thromboembolism [6]. However, a sufficient study has not yet been conducted. We previously reported that continued use of LDA did not increase risk of bleeding during or after ESD for early gastric cancer and decreased risk of ischemic events [13]. We also reported that patients with gastric epithelial neoplasms undergoing dialysis, those in whom the operation time was long and those in whom bleeding during ESD was poorly controlled were at high risk for post-ESD bleeding [14]. Ono et al. [24] and Matsumura et al. [25] similarly reported that continued administration of antiplatelet agents was not a risk factor for postoperative bleeding after gastric ESD. Results of other studies concerning risk of bleeding in patients undergoing gastric ESD are varied. Shindo et al. [26] reported that continued administration of antiplatelet agents, based on the guidelines, was not a risk factor for postoperative bleeding after gastric ESD; however, heparin replacement was identified as a significant risk factor.

Several studies have reported an increased risk of bleeding in patients who have undergone ESD for colorectal tumors. According to those previous reports, bleeding rates after the ESD procedure were between $1.7 \%$ and $6.3 \%$ [8-12], which was supported by our results. We previously reported that continued use of LDA increased risk of bleeding after ESD for CRNs compared with nonuse of anticoagulants/antiplatelets, but no significant difference was seen between the LDA-continued 
group and the LDA-interrupted group [15]. We also reported that colorectal tumor location in the rectum was a significant independent risk factor for delayed bleeding after ESD for colorectal tumors [27].

The limitations of our study were its retrospective nature, single center examining results from two colonoscopists, and small number of patients. Although there was no statistical significance in rate of bleeding after the procedure among the no-antithrombotics group and the DOAC group, the rate of bleeding after the procedure in the DOAC group was very high (22.2\%). If a large-scale study is conducted, the rate of bleeding after the procedure in patients who receive DOAC may be significantly higher than that in patients who receive no anticoagulants. A multicenter, prospective study with a large number of cases should be conducted in the future to determine whether the current Japanese guidelines are truly valid for patients.

Important factors in the endoscopic procedure for bleeding are the preoperative examination of a patient's overall medical condition, preoperative informed consent, arrangement of the apparatus and drugs for controlling bleeding, the surgeon's extensive experience with resection techniques, and postoperative management of the patient's condition. Therefore, we suggest that anticoagulants for patient undergoing colonoscopic treatment must be managed extremely cautiously. Several techniques (e.g., 8-ring method [28], mucosal incision method [29], two-channel method [30]) for complete closure of large resected ulcers after the ESD procedure have been demonstrated. These techniques may promote rapid ulcer healing and shield the exposed vessels on the artificial ulcer from mechanical trauma [30], although there is some possibility of reducing delayed bleeding. Recently, specific reversing agents for dabigatran (idarucizumab) have become available in Japan. Idarucizumab is an antibody fragment that completely reverses the anticoagulant effect of dabigatran within minutes [31]. In this study, bleeding occurred in two patients in the DOAC group when DOAC was resumed. Thus, idarucizumab may be one of the options if the patients using DOAC switch to dabigatran prior to ESD.

\section{Conclusion}

In conclusion, use of anticoagulants increased risk of bleeding in patients who underwent ESD for CRNs compared with those who did not use antithrombotics. In particular, careful attention to patients who took antiplatelets in addition to warfarin before ESD for CRNs is warranted.

\section{Competing interests}

None

\section{References}

[1] Wahl M]. Dental surgery in anticoagulated patients. Arch Intern Med 1998; 158: 1610 - 1616
[2] Garcia DA, Regan S, Henault LE et al. Risk of thromboembolism with short-term interruption of warfarin therapy. Arch Intern Med 2008; 168: $63-69$

[3] Anderson MA, Ben-Menachem T, Gan SI et al. Management of antithrombotic agents for endoscopic procedures. Gastrointest Endosc 2009; 70: 1060 - 1070

[4] Boustière C, Veitch A, Vanbiervliet G et al. European Society of Gastrointestinal Endoscopy (ESGE) guideline. Endoscopy 2011; 43: 445 461

[5] Veitch AM, Baglin TP, Gershlick AH et al. Guidelines for the management of anticoagulants and antiplatelet therapy in patients undergoing endoscopic procedures. Gut 2008; 57: 1322-1329

[6] Fujimoto K, Fujishiro M, Kato M et al. Guidelines for gastroenterological endoscopy in patients undergoing antithrombotic treatment. Dig Endosc 2014; 26: 1 - 14

[7] Oka S, Tanaka S, Kaneko I et al. Advantage of endoscopic submucosal dissection compared with EMR for early gastric cancer. Gastrointest Endosc 2006; 64: 877-883

[8] Shigita K, Oka S, Tanaka S et al. Long-term outcomes after endoscopic submucosal dissection for superficial colorectal tumors. Gastrointest Endosc 2017; 85: 546-553

[9] Boda K, Oka S, Tanaka S et al. Clinical outcome of endoscopic submucosal dissection for colorectal tumors. Gastrointest Endosc 2018; 87: $714-722$

[10] Oka S, Tanaka S, Saito Y et al. Local recurrence after endoscopic resection for large colorectal neoplasia: A multicenter prospective study in Japan. Am J Gastroenterol 2015; 110: 697 - 707

[11] Takeuchi Y, lishi H, Tanaka S et al. Factors associated with technical difficulties and adverse events of colorectal endoscopic submucosal dissection: Retrospective exploratory factor analysis of a multicenter prospective cohort. Int J Colorectal Dis 2014; 29: 1275-1284

[12] Oka S, Tanaka S, Kanao H et al. Current status in the occurrence of postoperative bleeding, perforation and residual/local recurrence during colonoscopic treatment in Japan. Dig Endosc 2010; 22: 376 380

[13] Sanomura Y, Oka S, Tanaka S et al. Continued use of low-dose aspirin does not increase the risk of bleeding during or after endoscopic submucosal dissection for early gastric cancer. Gastric Cancer 2014; 17: $489-496$

[14] Higashiyama M, Oka S, Tanaka S et al. Risk factors for bleeding after endoscopic submucosal dissection of gastric epithelial neoplasm. Dig Endosc 2011; 23: $290-295$

[15] Ninomiya Y, Oka S, Tanaka S et al. Risk of bleeding after endoscopic submucosal dissection for colorectal tumors in patients with continued use of low-dose aspirin. J Gastroenterol 2015; 50: 1041 - 1046

[16] Tajiri H, Kitano S. Complications associated with endoscopic mucosal resection: Definition of bleeding that can be viewed as accidental. Dig Endosc 2004; 16: $134-136$

[17] Fujita M, Shiotani A, Murao T et al. Safety of gastrointestinal endoscopic biopsy in patients taking antithrombotics. Dig Endosc 2015; 27: $25-29$

[18] Inoue T, Nishida T, Maekawa A et al. Clinical features of post-polypectomy bleeding associated with heparin bridge therapy. Dig Endosc 2014; 26: $243-249$

[19] Matsumoto M, Mabe K, Tsuda M et al. Multicenter study on hemorrhagic risk of heparin bridging therapy for periendoscopic thromboprophylaxis. BMC Gastroenterol 2015; 15: 89-96

[20] Hui AJ, Wong RM, Ching JY et al. Risk of colonoscopic polypectomy bleeding with anticoagulants and antiplatelet agents: Analysis of 1657 cases. Gastrointest Endosc 2004; 59: $44-48$

[21] Suzuki S, Chino A, Kishihara T et al. Risk factors for bleeding after endoscopic submucosal dissection of colorectal neoplasms. World J Gastroenterol 2014; 20: 1839-1845 
[22] Takeuchi T, Ota K, Harada S et al. The postoperative bleeding rate and its risk factors in patients on antithrombotic therapy who undergo gastric endoscopic submucosal dissection. BMC Gastroenterol 2013; 13: $136-143$

[23] Ruff CT, Giugliano RP, Braunwald E et al. Comparison of the efficacy and safety of new oral anticoagulants with warfarin in patients with atrial fibrillation: A meta-analysis of randomised trials. Lancet 2014; 383: $955-962$

[24] Ono S, Fujishiro M, Niimi K et al. Technical feasibility of endoscopic submucosal dissection for early gastric cancer in patients taking anticoagulants or anti-platelet agents. Digest Liver Dis 2009; 41: 725 728

[25] Matsumura T, Arai M, Maruoka D et al. Risk factors for early and delayed post-operative bleeding after endoscopic submucosal dissection of gastric neoplasms, including patients with continued use of antithrombotic agents. BMC Gastroenterol 2014; 14: $172-180$

[26] Shindo $\mathrm{Y}$, Matsumoto S, Miyatani $\mathrm{H}$ et al. Risk factors for postoperative bleeding after gastric endoscopic submucosal dissection in pa- tients under antithrombotics. World J Gastrointest Endosc 2016; 8: $349-356$

[27] Terasaki M, Tanaka S, Shigita K et al. Risk factors for delayed bleeding after endoscopic submucosal dissection for colorectal neoplasms. Int J Colorectal Dis 2014; 29: $877-882$

[28] Fujii T, Ono A, Fu KI. A novel endoscopic suturing technique using a specially designed so-called "8-ring" in combination with resolution clips (with video). Gastrointest Endosc 2007; 66: 1215-1220

[29] Otake Y, Saito Y, Sakamoto T et al. New closure technique for large mucosal defects after endoscopic submucosal dissection of colorectal tumors (with video). Gastrointest Endosc 2012; 75: 663-667

[30] Matsuda T, Fujii T, Emura F et al. Complete closure of a large defect after EMR of a lateral spreading colorectal tumor when using a twochannel colonoscope. Gastrointest Endosc 2004; 60: 836-838

[31] Pollack CV, Reilly PA, Eikelboom J et al. Idarucizumab for dabigatran reversal. N Engl J Med 2015; 373: 511-520 